\title{
Language Attitudes of Estonian Secondary School Students
}

\author{
Martin Ehala and Katrin Niglas \\ Tallinn University
}

\begin{abstract}
The results of a survey of language attitudes of Estonian secondary school students, ages 15 to 18, are presented, and the implications for the practice of language maintenance are discussed. The survey revealed that Estonian is valued as a token of identity but not much as a commodity in the sense of linguistic economy. It is argued that globalisation has changed the immediate communication domain from a national state level to a transnational level. Because of this global change, the traditional understanding of ethnolinguistic vitality may no longer be entirely adequate - the importance of subjective vitality factors gain importance over objective vitality factors. This means that in the near future, ideological issues concerning group identity become the key that determines which communities retain their language and which are to lose it.
\end{abstract}

Key words: language attitudes, ethnolinguistic vitality, language maintenance, Estonian

It is widely believed the 21 st century will witness a massive extinction of languages, with estimates ranging from $50 \%$ to $90 \%$ of living languages facing such a threat (see Crystal, 2000; Krauss, 1992). A typical endangered language is a minority language that has a poor support system and low economic value. National languages, however, are considered safe. Although there is some international recognition that smaller national languages may be threatened in a few domains, such as science and higher education, and "proper provision for linguistic diversity" (Communique, 2003, p. 6) is necessary, nobody really believes that any of these could become moribund within a few generations. Yet in our era of global information exchange and mobility, official language status by itself (even with all the necessary infrastructure) might not guarantee the ethnolinguistic vitality of a language if the attitudes of its speakers do not support it: the vast bulk of loss of linguistic di-

Correspondence should be sent to Martin Ehala, Tallinn University, Narva Rd. 25, Tallinn EE10120, Estonia. E-mail: ehala@tlu.ee 
versity is going to be due to voluntary language shift. To what extent it will affect national languages remains to be seen.

In this article we present the results of a large-scale survey of language attitudes of Estonian secondary school students, ages 15 to 18, and discuss the implications for the practice of language maintenance.

\section{LINGUISTIC SITUATION IN ESTONIA}

In 1816, serfdom was abolished in Estonia and the local population, mainly peasants, regained their personal freedom. As the dominant language in 19th century Estonia was German, upward social mobility of Estonians was often accompanied by language shift. About that time, the first attempts were made to establish Estonian as a language of culture. Back then, these attempts were seen as hopeless even by the national activists themselves who considered Estonian a dying language in their inner circle discussions (Undusk, 2004). Nevertheless, the language shift stopped, the national movement gained momentum, and at the beginning of the 20th century, Estonians were politically, economically, and culturally organised enough to achieve national independence in the War of Independence (1918-1920). In the newly established Estonian Republic (1918-1940), Estonian became the official language and was used in all walks of life.

During the period of Soviet occupation (1940-1941, 1944-1991), Russian gradually became the dominant language in Estonia. Although Estonian remained the official language (besides Russian) and its usage was not restricted much in the field of culture and education (including higher education), Russian was extensively used in the country's administration and economic management. This was accompanied by a large-scale immigration of Russian-speaking people that made up $40 \%$ of the Estonian populace by the end of the occupation. Although Russian was taught extensively in schools as a second language and its usage was politically encouraged, with the aim of most Estonians becoming bilingual, no significant language shift occurred.

In 1991, the linguistic situation changed once more. Estonia regained independence in the so-called "singing revolution" and Estonian became the only official language again. Although Russian lost its official status, it is nevertheless quite widely used in larger cities. Due to globalisation, English has become quite prominent in Estonia, especially among the younger generation. At present, Estonian is a well developed literary language which functions in all spheres of social life, increasingly including such a costly field as language technology. Since May 2004, Estonian is also one of the official languages of the European Union. Currently there are around 900,000 Estonian native speakers living in Estonia.

Estonian could thus hardly be considered an endangered language. However, as the results of this survey reveal, approximately one quarter of young Estonians are 
rather pessimistic about the future of their language. For example, $25.5 \%$ of the respondents of this study agreed that "by the time your child will have grown up, the Estonian language will have no practical importance in the work life." At least to some extent, this could affect the ethnolinguistic vitality of Estonian in the future.

\section{THEORETICAL BACKGROUND}

Surveying language attitudes has a long history and a number of approaches have been developed. In a comprehensive overview of the field, Garrett, Coupland, and Williams (2003) divide them into direct and indirect methods. The most widespread direct approaches make use of interviews and questionnaires. Both have been criticised for their obtrusiveness which can cause a bias. The indirect approaches use variants of the matched guise test (Lambert, Hodgson, Garner, \& Fillenbaum, 1960) and observation. Although less biased, they allow only a general assessment of the language attitudes, whereas questionnaires and interviews can provide more detailed accounts. For this study, two direct approaches to language attitudes are of particular interest: the subjective ethnolinguistic vitality tests (Allard \& Landry, 1986; Bourhis, Yvon, \& Rosenthal, 1981) and the model developed by Colin Baker (1992).

The classic questionnaire is the Subjective Vitality Questionnaire for ethnolinguistic groups designed by Bourhis et al.(1981). This questionnaire is based on the taxonomy of the structural variables affecting ethnolinguistic vitality proposed by Giles, Bourhis, and Taylor (1977). It thus contains questions pertaining to the status factors, demographic factors, and institutional support and control factors of the in-group and significant out-group language. Later Allard and Landry (1986) developed a 24-item version of the Beliefs on Ethnolinguistic Vitality Questionnaire (BEVQ). This questionnaire was also based on Giles et al. (1977), but was modified according to the typology of beliefs elaborated by Kreitler and Kreitler $(1976,1982)$ : (a) general beliefs about how things are, (b) normative beliefs concerning what should exist, (c) personal beliefs about one's own behaviour, and (d) goal beliefs about one's desire to behave in a particular way. The BEVQ has since been applied (with modifications) in different settings (Allard \& Landry, 1994; Evans, 1996; Kam, 2002). The main weakness of this model is that it measures respondents' assessment of objective ethnolinguistic vitality only. However, one's assessment of the vitality of one's own language need not fully coincide with his or her attitude toward the language - although the language is poorly developed, one may still love it (or vice versa).

This paradox is connected with a widely held distinction between instrumental and integrative attitudes toward a language (see Baker, 1992; Gardner, 1985). Instrumental attitudes follow pragmatic, utilitarian motives. A language is instrumentally highly valued if its knowledge provides economic or status advantages. 
Integrative attitudes are directed toward social networking and collective identity. A language is integratively highly valued if its knowledge provides identification with important others.

Baker (1992) has developed a model that is more responsive to these factors. Graphically it can be presented as in Figure 1. (We have slightly simplified the graphics of Baker 1992, p. 70, for the sake of exposition.)

As the figure shows, social variables are the main determinants of the type of culture with which one is associated. Most important of those factors were Language Background which was strongly associated with Welsh and Literary Culture. The type of culture in turn was correlated with Attitudes to Welsh. The correlation of Attitudes to Welsh and Welsh and Literary Culture was particularly strong. Interestingly, Language Ability and Attitudes to Welsh were found not to be correlated (Baker, 1992, pp. 69-72).

Although Baker's (1992) model was developed for the Welsh situation, it could be generalised to explain language attitudes in other settings too. The only culture-specific categories in his model are Welsh and Literary Culture and Popular Culture. Actually, both these categories manifest a more general relationship between the minority and majority cultures in a bicultural setting. In a bilingual society, people have access to both of these cultures, and sociodemographic factors determine which of the two cultures one associates with more strongly. This association to a particular culture in turn influences both the instrumental and integrative attitudes toward the corresponding languages. Thus the model developed by Baker could be reformulated on a more general level, as in Figure 2.

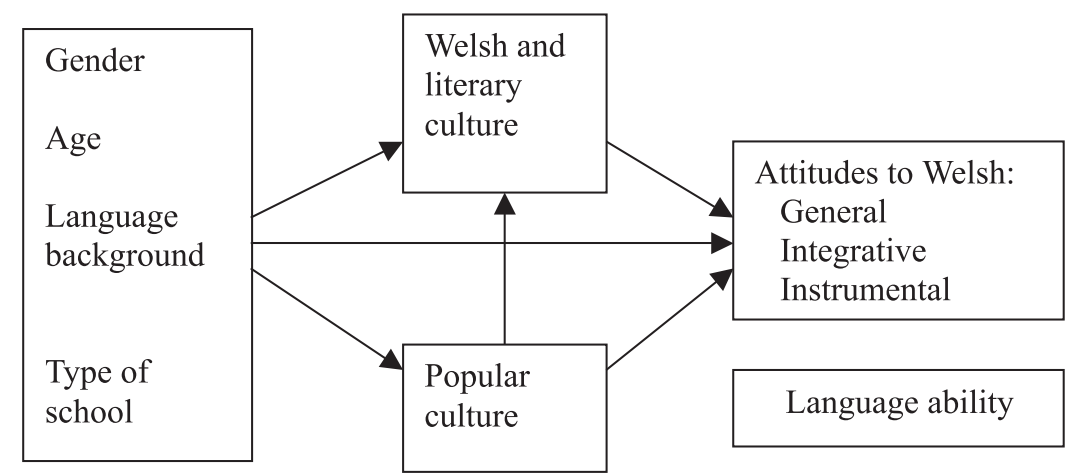

FIGURE 1 Baker's (1992) model of language attitudes to Welsh. Adapted from Attitudes and Languages by C. Baker, ( $) 1992$, published by Multilingual Matters, Clevedon, England. Used with permission. 


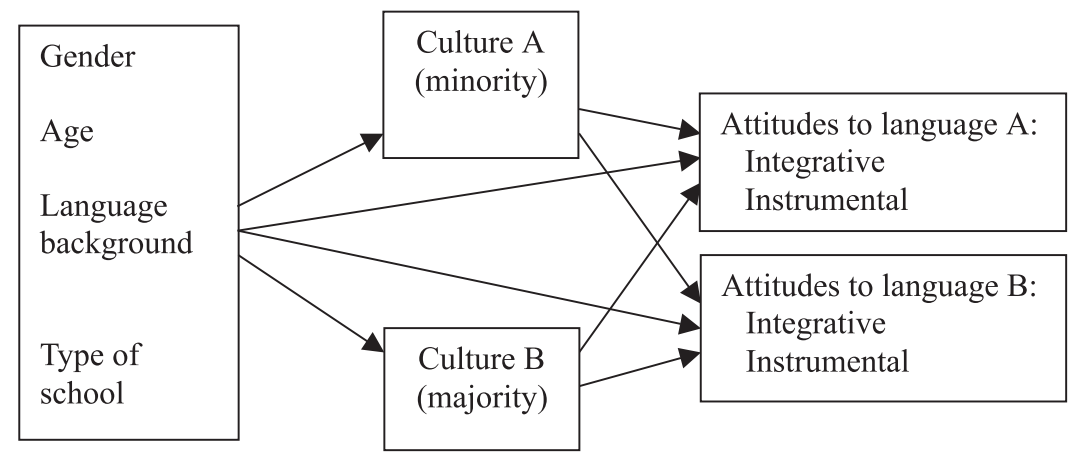

FIGURE 2 General model of language attitudes. Adapted from Attitudes and Languages by C. Baker, ( $)$ 1992, published by Multilingual Matters, Clevedon, England. Used with permission.

The notions of minority and majority are understood very broadly in Figure 2. These terms could as well be relabelled as low status and high status cultures respectively. What is important is that there is a bicultural setting with two corresponding languages and one of them has higher status than the other. The status difference may be large, or it may be quite marginal, depending on each particular case. Although the model presents cultures A and B as distinct entities with clear boundaries, in reality the situation is more likely to be complex allowing multiple memberships and hybrid identities.

Pavlenko (2002) has criticised the sociopsychological models (such as the one discussed earlier) for being too rigid to account for the versatile nature of cultural contact situations. She also criticises the main methodologies (surveys, questionnaires) that have been widely used in studies of language attitudes and linguistic behaviour in multilingual settings. Instead, she suggests that the linguistic behaviour in contact situations should be analysed by (preferably longitudinal) ethnographic studies taking the particulars of the social context of language use into account (Pavlenko, 2002). Although agreeing with the notion of abstractness of theoretical models and the limitations of survey methods outlined by Pavlenko, we believe that the "poststructuralist" methods sensitive to power relations and discursive particulars that shape language attitudes are best viewed as complementary to the more traditional methods. The questionnaires allow generalising over a large population and if the interpretation of the results remains ambiguous, this only raises new research questions for refinement by poststructuralist methods.

Thus, despite the limitations of the traditional methodology for the study of attitudes, the framework outlined earlier is taken as the basis for investigating secondary school students' attitudes toward Estonian in a bicultural context with English. The questionnaire consisted of 44 items, designed to measure the associations 
among English-mediated commercial culture, the instrumental attitudes toward both Estonian and English, and the integrative attitudes toward Estonian. Nine additional questions studied the sociodemographic background (age, sex, first language, county, type of settlement, family income, parents' education, parents' ethnicity, curriculum type [normal, extended in English language teaching, extended in some other subject]).

\section{THE SAMPLE}

The aim of the study was to explore the language attitudes of all young people who consider Estonian their mother tongue. Therefore it was decided to design the study as a sampling survey which allows making inferences to the whole population on the basis of a carefully chosen subset. In this inquiry, a two-phase sampling scheme, combining stratified and cluster sampling, was used to ensure the representativeness of the sample mainly by different regions of Estonia and gender. The authors presume that these two demographic variables influence the language attitudes of young people the most. The counties of Estonia were used as strata.

The clusters in the sampling scheme were the schools, where at least one school from the centre of the local administrative unit and one from the countryside were chosen from every county ( 48 schools altogether, of which 3 refused to participate). The representativeness by gender was guaranteed by the fact that in Estonia, schools and classrooms are usually mixed. As previous studies (see de Bot \& Stoessel, 2002; Valk, 1998) have indicated, the special importance of language attitudes of teenagers, the subjects of the study, were chosen from 10th and 12th graders. As a result of the clustering application on the second phase of sampling - where one class of 10th graders and one class of 12th graders were chosen from every school in the sample-the size of the sample was 1,964 students, of whom 1,887 indicated Estonian as their mother tongue.

According to the demographic background variables, there was an approximately even number of 10th graders and 12th graders in the sample, and $41.7 \%$ of the respondents were boys. One third of the respondents were from big cities ( $18.1 \%$ from Tallinn, the capital of Estonia, and $10.0 \%$ from Tartu, the second biggest town in Estonia), one third from county centres, and one third from the rural areas. Family incomes were assessed to be above average for $18 \%$ and below average for $16 \%$ of students. There were $21.6 \%$ respondents whose parents both had higher education, $27.5 \%$ had one parent with higher education, $42.3 \%$ had both parents with secondary school level education, and $8.7 \%$ reported some other educational level for their parents. Of the respondents, $88.2 \%$ considered both parents Estonians, whereas 3.5\% reported that neither parent is Estonian. It is interesting to compare these figures with the fact that $97 \%$ of respondents considered Estonian their mother tongue (2.8\% indicated Russian, and $0.3 \%$ other). As the answers of 
the sub-samples with different mother tongues varied significantly, only those who indicated Estonian as their mother tongue are included in the following analysis.

Thus, in the final sample used for this analysis, there are 1,887 respondents from 45 secondary schools all over Estonia. As only three schools refused to participate in the study and there were no serious problems reported regarding the students answering the questionnaires, it can be concluded that the sample is sufficiently unbiased to allow inferences to the population described earlier.

\section{DATA ANALYSIS}

Data analysis was conducted using SPSS (Statistical Package for the Social Sciences). First simple frequency tables and descriptive statistics were used to get an overview of the mean levels and distribution of all variables. The questionnaire was relatively detailed, including 44 items connected to the use of Estonian and English either in everyday life or in the workplace. The scope of this article does not allow a thorough analysis of every single variable, but as it was assumed that the single items can be grouped to get more reliable indicators for language attitudes, we concentrate our discussion on the summary variables.

To study the relations among initial variables and to reveal the latent phenomena underlying these relations, factor analysis was used. Variables that are correlated with one another but largely independent of other subsets of variables are combined into summary variables called factors which are thought to reflect the underlying processes that have created the correlations among initial variables (Tabachnic \& Fidell, 1996, p. 635). Factor analysis, when applied to a set of variables, helps to discover which variables form coherent subsets that are relatively independent of one another. In this study, the results of several types of factor analysis were compared to find the best possible solution for summary variables. As the correlations between initial variables were not very strong, the principal components, as well as the maximum likelihood methods, produced 12 initial factors with eigenvalues over 1. Six variables with low commonalities were excluded from the model, which lowered the number of factors to 11 . As the principal components extraction with varimax rotation produced a set of factors which was the easiest to interpret and was also superior by statistical parameters, it was decided to persevere with this traditional type of factor analysis. Statistical parameters considered were the communalities of the initial variables, the cumulative proportion of variance described by the factor model, the evenness of the distribution of initial variables between factors, and the proportions of variance described by each factor.

It is not very common to operate with such a large number of factors, and it can be surmised that the factors with only a few initial variables are not statistically reliable. However, as all the factors had bigger variances than the initial variables (eigenvalue 
TABLE 1

Summary Variables

\begin{tabular}{ll}
\hline Factor & \multicolumn{1}{c}{ Summary Variable } \\
\hline F1 & The intensity of English usage \\
F2 & Preferring English for pragmatic reasons \\
F3 & Voluntary language care \\
F4 & English in work environment \\
F5 & Estonian as a working language at the local office of a foreign company \\
F6 & Availability of education in English \\
F7 & The prestige of education in English \\
F8 & Increasing language instruction \\
F9 & Ethnic openness \\
F10 & Close contacts with non-Estonians \\
F11 & Usage of Estonian in a mixed family \\
\hline
\end{tabular}

$>1$ ), it was considered useful to base the analysis on sets of variables and not to operate with single items. The 11 factors that emerged are presented in Table 1.

On the other hand, we noticed that these 11 factors could be grouped into four thematic categories: (a) attachment to the English-mediated commercial culture (F1), (b) general language loyalty (F2, F3, F4, F5), (c) the choice of language in education (F6, F7, F8), and (d) disposition toward cross-cultural communication with local non-Estonians (F9, F10, F11). To see whether the merging of some factors would raise the reliability, the statistic Cronbach's alpha was calculated for every set of variables forming the basis for 11 factors. Four sets had a $>0.7$, five sets had a between 0.5 and 0.7 , and two sets had a $<0.5$. Thereafter smaller factors were merged with bigger ones according to thematic groups and new alphas were calculated. Because for all merged sets of variables, the Cronbach alphas were considerably lower than for initial bigger factors, it was decided to accept the model with 11 factors based on 38 initial variables.

From the 11 factors, 5 (F1, F2, F4, F7, and F11) are relevant to the model in Figure 2. These factors are presented in Appendix A: we have listed the initial variables most strongly related to a particular factor (given factor loadings can be interpreted as a correlation between the initial variable and the factor). The frequencies presented for every factor are the average values calculated over initial variables.

\section{RESULTS}

The factors in this study relate to the model presented in Figure 2 as follows: F1 indicates association with the English-mediated culture, F2 and F7 express instrumental attitudes toward English, and F4 and F11 express integrative attitudes to- 
ward Estonian. The remaining factors are not directly linked to this model and are not considered here.

The first factor (F1) measured the intensity of English usage in daily life. According to the results, about $18 \%$ of respondents use English intensively (see Appendix A). By sociodemographic factors, the general trend was that the larger the settlement (town or city), and the wealthier or better educated the parents, the higher the intensity of daily English usage. Not surprisingly, students from classrooms with an extended English curriculum claimed to use English more extensively. As there is no English minority in Estonia, F1 expresses the usage of English between native Estonians. Such usage is integrative rather than instrumental. Thus, the intensity of English usage indirectly indicates the strength of one's association with the global English-mediated culture.

F2 illustrates to what extent young Estonians are prepared to make a mental or financial effort to maintain the usage of Estonian in their immediate environment. Such an effort is necessary for a language to function as an instrument in a competitive bilingual environment. Thus, if people are willing to use Estonian in a situation where it would be easier or cheaper to use English, it indirectly manifests their positive instrumental attitudes to this language.

The results in F2 show that 54\% of respondents would prefer English if using Estonian in a given situation would require an extra effort or cause an additional cost. Sociodemographically the results are similar to F1: students from English-biased classes and from larger cities (first and above from the capital Tallinn) tend to prefer English more than the rest; the same tendency is evident in students whose parents are better off or have higher education levels. Older students are more pragmatic than younger ones, and boys more pragmatic than girls. The similarity between the results of F1 and F2 indicates that the more intensively one uses English, the more likely one is to prefer English over Estonian. Thus, the preference of Estonian seems to depend on a person's weak language proficiency in English rather than on the positive instrumental attitude toward Estonian.

The variables in $\mathrm{F} 4$ ask the respondents to choose the language in imaginary communicative situations in business where power relations are at play. The choice of English overEstonian in these situations does not provide any immediate instrumental advantage, but it would be a sign of one particular type of speech accommodation, the so-called referee design (Bell, 2001) in which one accommodates to a group's language when this group itself is absent in the communicative situation. Such an accommodation is a statement about one's collective identity and thus indirectly manifests the person's integrative attitudes toward the languages in competition.

The results of F4 indicate that 32\% of participants would rather use English in these work situations (see Appendix A). In contrast with the previous factors, in F3, English had a higher acceptance rate among the respondents who live in rural areas and whose parents' education level is below the average. The participants whose parents had higher educational levels reported a lower acceptance level for 
English. This suggests that the participants with an educated family background have higher collective self-esteem than respondents from lower social strata.

F7 includes the questions exemplifying the importance the students give to education in English, particularly for their future children. The choice of the language of education reveals indirectly the instrumental attitudes toward Estonian and English. The results revealed that as much as $12 \%$ of the participants would definitely choose English-mediated education for their children, and an additional $32 \%$ stated that they would rather do so. A total of $44 \%$ favouring English education is quite a large proportion. Particularly in favour of education in English were those who studied in an English-biased curriculum themselves, as well as those whose families were better off than the average. If the respondents would in fact act in the future according to their attitudes revealed in the survey, this would probably signify a language shift. On the other hand, the relationship between attitudes and behaviour is not straightforward. Garrett et al. (2003) outline a number of factors that may cause discrepancy between them: one may express socially favourable attitudes, one may be prevented from behaving according to one's attitudes, one's attitudes may be in competition, and one may change one's attitudes before the time comes to act, and so forth. Thus, what the results of F7 most probably reflect is just the enormous importance the youth in question assign to English language competence in the world of the future.

The variables in F11 measured the respondents' willingness to use Estonian in their future married life in case the respondents' spouse is not a native Estonian. Only $14 \%$ of the respondents stated that using Estonian is not important in their family, like conveying the language to their children. This factor definitely expresses the integrative attitudes of the respondents to Estonian. Comparing this result with the results of factors measuring instrumental attitudes (F2, F7), it appears that only $46 \%$ (F2) and 56\% (F7) hold positive instrumental attitudes to Estonian, whereas as much as $86 \%$ (F11) hold positive integrative attitudes.

Further analysis of the results revealed that sociodemographic factors are indeed associated with the type of culture $(\mathrm{F} 1)$ as well as with language attitudes $(\mathrm{F} 2$, F4, F7, F11). Appendix B presents the statistically significant differences in response to the aforementioned five factors. Presented in this appendix are only those sociodemographic parameters that proved to be statistically significant determiners of attitudes. The summary of results is presented in Figure 3.

School type, settlement type, and parents' income and education proved to be significant determinants for students' association with English culture (expressed by the intensity of the daily usage of English). Urban students (particularly if they attended an English-biased school) from well-off families with both university-educated parents, had a significantly higher usage of English than rural students whose parents' educational level and income were low. The same sociodemographic profiles also yield to different language attitudes: well-off urban youth favour English over Estonian for pragmatic reasons and in education, 


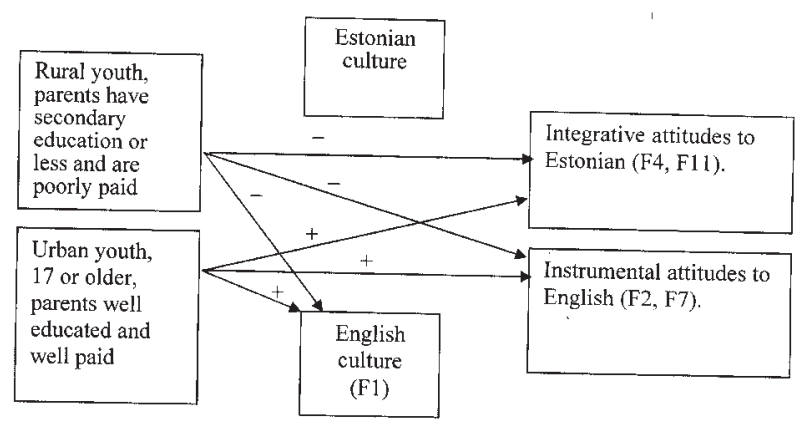

FIGURE 3 Summary of effects on attitudes to English and Estonian.

whereas the youth from rural areas favour Estonian. On the other hand, the urban youth also value Estonian as a token of identity more than the rural youth.

To better understand the relations between sociodemographic factors and attitudes, we conducted a cluster analysis on the basis of the same factors (F1, F2, F4, F7, F11). Because of the large number of cases, k-means cluster analysis was preferred to hierarchical cluster analysis. Various models were calculated and compared to find the best solution. In addition to the interpretability of the emerged set of clusters, the following statistical criteria were considered: reasonableness of cluster sizes, equability of influences of different factors to the results of clustering as measured by an analysis of variance, and the clear difference between clusters as described by cluster centre values. Statistically and by the sociodemographic profiles, the most illuminative model appeared to be the one with five clusters produced by k-means cluster analysis, with unfixed cluster centres and iteration with running means (see Table 2). In this table, the figures express the deviation of cluster centres from the average. Positive values express deviation toward the more positive attitude (or attachment in the case of F1), compared to the average, and vice versa. Note that the scale of F4 is inverted to give a uniform expression.

The sociodemographic profiles and language attitudes of the clusters could be characterized as follows:

C1. A typical member of this cluster is male and lives in the capital Tallinn, his parents have higher education, but their income is below average which indicates that they are probably employed in the public sector (teachers, doctors, clerks, etc). He attends a school with an extended curriculum in some subjects which indicates that his parents value good education. He uses English daily. His integrative attitudes to Estonian are positive, and he does not overemphasize the importance of English as the medium of education. On the other hand, he is most likely to prefer 
TABLE 2

Clusters on Attitudes to English and Estonian

\begin{tabular}{llrrrrr}
\hline & & \multicolumn{5}{c}{ Clusters } \\
\cline { 3 - 7 } & & \multicolumn{1}{c}{ C1 } & \multicolumn{1}{c}{ C2 } & \multicolumn{1}{c}{ C3 } & \multicolumn{1}{c}{ C4 } & \multicolumn{1}{c}{ C5 } \\
\hline Attachment to English culture & $\mathrm{F} 1$ & .22 & -.40 & .11 & -.53 & .72 \\
Instrumental attitudes to English & $\mathrm{F} 2$ & .79 & .35 & .16 & -.85 & -.30 \\
& $\mathrm{~F} 7$ & -.42 & .12 & -.31 & -.28 & 1.24 \\
Integrative attitudes to Estonian & $\mathrm{F} 44^{\mathrm{a}}$ & .57 & .17 & -1.36 & .26 & .06 \\
& $\mathrm{~F} 11$ & .47 & -1.51 & .08 & .24 & .20 \\
\hline
\end{tabular}

aThe scale for F4 is inverted.

English if it would save him money. Twenty-four percent of the respondents belong to this cluster.

C2. A typical member is male and lives in the countryside, his parents have low-level education, but their income is above the average (the income here is a perceived estimation of the participants and does not reflect the actual income which is generally lower in rural areas). He attends an average school with no extended curriculum. He does not use English every day, however his instrumental attitudes to English are well above average. As for the integrative attitudes to Estonian, he has the lowest score. Fifteen percent of the respondents belong to this cluster.

C3. A typical member of this cluster is a rural youth, about 16 years old, whose parents have a low income and not much education. He or she attends an average school and does not use much English. His or her language attitudes are average, except that in work situations he or she would accommodate to English the most. Knowing that he or she is from a poor rural family and younger than the average age in this study, his or her tendency to accommodate might come from the naïve wish to keep a job at any cost, rather than from low integrative attitudes to Estonian. Eighteen percent of the respondents belong to this cluster.

C4. He or she lives in a city other than the capital Tallinn, his or her parents have average education and income. He or she attends a school with an extended curriculum indicating that the family values good education. He or she is not attached to English at all, does not overemphasize its instrumental importance, and has positive integrative attitudes toward Estonian. Cluster 4 is the most Estonian-centred cluster. Twenty-six percent of the respondents belong to this cluster.

C5. A typical member of this cluster is a girl, living in the capital Tallinn or in a town, attending a school with extended English tuition. At least one parent has a high education level, and the income of the family is well above average. Cluster 5 is the cluster that is most attached to English, and the members follow the trends of international youth culture. She has average integrative attitudes toward Estonian, 
but has the highest preference for education in English. Seventeen percent of the respondents belong to this cluster.

As seen, the five clusters are distinguished clearly by the strength of their attachment to Estonian as well as attitudes to English. The significant differences between clusters indicate that there is no single and uniform Estonian identity for the population studied, similarly as there is no "dichotomous and absolute Welshness" as argued in Garrett et al. (2003, p. 215). Although the attachment to English is clearly less apparent in Estonia than in Wales, the differences seem to be quantitative rather than qualitative.

\section{DISCUSSION}

The results of the survey indicate that about 18\% of young Estonians use English intensively in their daily activities (F1). Quite a number of respondents (25\%) agree that in about 30 years, Estonian might have lost currency in business spheres. Even a larger number (44\%, F7) would prefer to educate their children in English. Such results are surely a sign that Estonian is not very highly valued amongst the youth as a usable tool, as a commodity in the sense of linguistic economy (Coulmas, 1992; Grin 1996). Or to put it differently, a large proportion of young Estonians assign a low instrumental value to Estonian.

If we look more closely at the groups of respondents whose instrumental attitudes to Estonian are low, it appears that typically they are from a well-off family $(\mathrm{C} 2, \mathrm{C} 5)$, living in the capital and attending schools with an extended English curriculum (C5). These schools are known in Estonia as elite schools, and they are valued among parents who would like to see their children in well-paid jobs. As good knowledge of English is a must for a successful career in business or politics in Estonia, mastering this language means obtaining linguistic capital that one can exchange for other types of capital, to express it in Bourdieu's (1999) terms. In this context, it is not surprising that the elite youth assign such high instrumental value to English. The question is whether this could have an impact on the vitality of Estonian.

David Li (2004) argues that one of the factors promoting the spread of English worldwide is the "utilitarian discourse system" (Scollon \& Scollon, 1995). The most important principles in this discourse system for our discussion are the following: (a) humans are defined as rational economic entities, (b) "good" is defined as what will give the greatest happiness to the greatest number, and (c) values are established by statistical (i.e. quantitative) means. Given these utilitarian principles, there would be no need for more than one language in one's immediate space of communication.

Before the information age, the borders of a national state tended to define the maximal sphere of communication for most people. Thus, given the utilitarian principles, the usage of national languages was "natural" or sensible, but this did 
not apply in case of minority languages, as using them within the state domain could not be considered rational. At present, the situation has changed. Communication has become global or at least regional, stretching across the borders of national states. In this situation, the utilitarian principle starts to argue for one single language, undeniably for the one which is economically the most powerful, and has the highest commodity value in a given region. This would apply pressure to all weaker languages, be it traditional minority languages or smaller national ones.

The main counterforce that works for language maintenance is the need for collective identity. Collective identity is based on the culture and history of a particular ethnolinguistic community. The richer it is, that is, the more symbolic power it has, the stronger and more distinct identity it is capable of providing (see Smith, 1999). The strength of identity is the main reason (besides geographic isolation) why some peripheral languages have managed to survive historically while the expansion of a hegemonic language (such as Latin) has replaced the rest of the original languages in its periphery by pidgins (Gunaratne, 2004).

As globalisation is steadily ending the isolation of ethnic communities, the ideological issues concerning group identity become the key that determines which communities retain their language and which are to lose it. At the base level, everything depends on the economic surplus that the community is able to produce. Without a surplus nothing can be spent on culture, ideology, and a linguistic support system that are necessary for developing a positive group identity. On the other hand, if there is a surplus, the maintenance of a language depends on the willingness to actually spend this surplus for developing a positive group identity. This in turn depends on the value that this particular identity can already provide to its members. Thus, there is a cycle of mutual dependency: the expenditure for developing a positive group identity enhances the sense of positive group identity, which is a prerequisite for a social consensus that the expenditure for maintaining this identity is worthwhile in the first place.

This can be vividly illustrated in the case of Estonian. Assessing the objective ethno-linguistic vitality of Estonian, the language would no doubt be classified as a language of high vitality, despite the relatively small number of speakers $(900,000)$ and low birth rate. At the same time, it is clear that if the language attitudes of the Estonian younger generation does not change, they start to influence the objective vitality of Estonian in the near future.

The educational sphere is the most critical. A demand for English-language instruction in schools and universities by the successful and influential stratum of society would be a clear signal of devaluation of Estonian as an educational tool. This would lead to a decrease of the number of students instructed in Estonian which in turn would make it harder to provide quality education in this language, particularly if higher education does not provide support. This in turn will devalue Estonian schools further, creating a snowball effect that may lead to a disintegration of the support system for Estonian on a much larger scale. 
The paradox is that the same students who do not see instrumental value for Estonian in the near future still value it in integrative terms: only 14\% (F11, C2) would consider not using Estonian with their spouse and child if they would happen to marry a non-Estonian. This is three times less than those who would consider providing education for their child in English. They would thus like to keep Estonian for their identity purposes and use English in business matters: a conflict of emotions and reason.

There are a couple of implications of the results of this study for the practice of language maintenance. First, language maintenance is not only relevant for minority languages, although they are no doubt in greatest danger. Smaller national communities should also take care of the maintenance of their language. Second, attitudinal factors become even more decisive in language maintenance, as increasingly more potential collective identities compete over where people actually belong. According to Pavlenko (2002, p. 296), language attitudes could be explained "through the ways in which everyday social practices" present the languages and identities in competition. Careful poststructuralist analyses could reveal the critical aspects of the discourses in each contact situation. Based on these findings, it could be possible to influence the discourse to facilitate language maintenance. Coordinated activities of the educational system and public broadcasting would be the most important in this respect. How this should be achieved goes beyond the scope of this article.

\section{CONCLUSION}

The article discussed the results of a large-scale survey of the attitudes of Estonian secondary school students. The results revealed that a large proportion (18\%) of the students from the capital, having a wealthy and well-educated family background, use English intensively in peer-group communication and would prefer English as the language of instruction in the educational system. The study also revealed that another group (15\%) with a wealthy but uneducated family background, living in rural areas, has significantly low integrative attitudes toward Estonian.

These rather negative attitudes were surprising in the light of the fact that by the objective criteria, Estonian could be considered a vital and well-developed language functioning in all spheres of social life. This discrepancy between objective and subjective vitality can be explained by the emergence of global information exchange which has widened the immediate information sphere from the national to the international level. This has brought some very attractive collective identities to the attention of the Estonian youth, and the social comparison that this has provided has not been in favour of Estonian. This indicates that attitudinal factors are becoming more important for language maintenance and loss. In this process, the objective vitality criteria get reduced to necessary but not sufficient conditions 
for language perpetuation. As a consequence, conscious development of language attitudes is likely to become a routine part of language policy and planning.

\section{ACKNOWLEDGMENTS}

This study was carried out as a part of the research project "The Analysis, Modelling and Control of the Development of the Estonian Linguistic Environment" (reg.: 0132493s03), and it was supported by Estonian Science Foundation Grant 6148. We thank all schools that agreed to participate in the project as well as the students of the Tallinn University for entering the statistical data.

\section{REFERENCES}

Allard, R., \& Landry, R. (1986). Subjective ethnolinguistic vitality viewed as a belief system. Journal of Multilingual and Multicultural Development, 7, 1-12.

Allard, R., \& Landry, R. (1994). Subjective ethnolinguistic vitality: A comparison of two measures. International Journal of the Sociology of Language, 108, 117-144.

Baker, C. (1992). Attitudes and language. Clevedon, England: Multilingual Matters.

Bell, A. (2001). Back in style: Reworking audience design. In P. Eckert \& J. R. Rickford (Eds.), Style and sociolinguistic variation (pp. 139-169). Cambridge, England: Cambridge University Press.

Bourdieu, P. (1999). Language and symbolic power. Cambridge, MA: Polity Press.

Bourhis, R., Yvon, H. G., \& Rosenthal, D. (1981). Notes on construction of a 'subjective vitality questionnaire' for ethnolinguistic groups. Journal of Multilingual and Multicultural Development, 2, 45-155.

de Bot, K., \& Stoessel, S. (2002). Introduction: Language change and social networks. International Journal of the Sociology of Language, 153, 1-7.

Communique. (2003, September 19). Realising the European Higher Education Area. Communique of the Conference of Ministers Responsible for Higher Education, Berlin, Germany.

Coulmas, F. (1992). Language and economy. Oxford, England: Blackwell.

Crystal, D. (2000). Language death. Cambridge, England: Cambridge University Press.

Evans, C. (1996). Ethnolinguistic vitality, prejudice, and family language transmission. The Bilingual Research Journal, 20, 177-207.

Gardner, R. C. (1985) Social psychology and second language learning: The role of attitudes and motivation. London: Edward Arnold.

Garrett, P., Coupland, N., \& Williams, A. (2003) Investigating language attitudes: Social meanings of dialect, ethnicity and performance. Cardiff: University of Wales Press.

Giles, H., Bourhis, R., \& Taylor, D. (1977). Towards a theory language in ethnic group relations. In H. Giles (Ed.), Language, ethnicity and intergroup relations (pp. 307-348). London: Academic.

Grin, F. (1996). Economic approaches to language and language planning. An Introduction. International Journal of the Sociology of Language, 121, 1-16.

Gunaratne, S. A. (2004). Proto-Indo-European expansion, rise of English, and the international language order: A humanocentric analysis. International Journal of the Sociology of Language, 164, 1-32.

Kam, M. C. (2002, December). Motivation in second language learning: Ethnolinguistic vitality or psychological construct that counts? Paper presented at the Australian Association for Research in Education Conference Problematic Futures: Educational Research in an Era of ... Uncertainty, Brisbane, Australia. Retrieved June 29, 2006, from http://www.aare.edu.au/02pap/kam02261.htm

Krauss, M. (1992). The world's languages in crisis. Language, 68, 4-10.

Kreitler, H., \& Kreitler, S. (1976). Cognitive orientation and behavior. New York: Springer. 
Kreitler, H., \& Kreitler, S. (1982). The theory of cognitive orientation: Widening in the scope of behaviour prediction. In B. Maher \& W. Maher (Eds.), Progress in experimental personality research (Vol. 11, pp. 101-169). New York: Academic.

Lambert, W., Hodgson, R. C., Garner, R. C., \& Fillenbaum, S. (1960). Evaluational reactions to spoken language. Journal of Abnormal and Social Psychology, 60, 44-51.

Li, D. (2004). Between English and Esperanto: What does it take to be a world language. International Journal of the Sociology of Language, 164, 33-64.

Pavlenko, A. (2002). Poststructuralist approaches to the study of social factors in second language learning and use. In V. Cook (Ed.), Portraits of the L2 user (pp. 275- 302). Clevedon, England: Multilingual Matters.

Scollon, R., \& Scollon, S. (1995). Intercultural communication: A discourse approach. Oxford, England: Blackwell.

Smith, A. D. (1999). Myths and memories of the nation. New York: Oxford University Press.

Tabachnick, B. G., \& Fidell, L. S. (1996). Using multivariate statistics (3rd ed). New York: HarperCollins.

Undusk, J. (2004). Eksistentsiaalne Kreutzwald [Existential Kreutzwald]. Vikerkaar, 10/11, 133-152.

Valk, A. (1998). Mitte-eesti noorte psühholoogiline kohanemine mitmerahvuselises klassis: enesehinnang ja etniline identiteet [Psychological adjustment of non-Estonian youth in multiethnic classrooms: Self-esteem and ethnic identity]. In M. Lauristin, S. Vare, T. Pedastsaar, \& M. Pavelson (Eds.), Mitmekultuuriline Eesti: väljakutse haridusele (pp. 401-426). Tartu, Estonia: Tartu Ülikool.

\section{APPENDIX A}

Factors With Initial Variables ${ }^{a}$

\begin{tabular}{|c|c|c|c|c|}
\hline F1: Intensity of English Usage in Daily Life & & & & $\begin{array}{l}\text { Factor } \\
\text { Loadings }\end{array}$ \\
\hline Do you speak English with your friends? & & & & 0.76 \\
\hline $\begin{array}{l}\text { Is it easier for you to express emotions (surprise, } \\
\text { love, anger) in English? }\end{array}$ & & & & 0.70 \\
\hline Do you think in English? & & & & 0.68 \\
\hline $\begin{array}{l}\text { Do you use English on the Internet (in } \\
\text { chatrooms, e-mails)? }\end{array}$ & & & & 0.59 \\
\hline $\begin{array}{l}\text { Do you read English materials (books, } \\
\text { magazines, comics) for recreation? }\end{array}$ & & & & $(0.49)$ \\
\hline always & often & sometimes & seldom & never \\
\hline $3 \%$ & $15 \%$ & $29 \%$ & $33 \%$ & $21 \%$ \\
\hline F2: Preferring English for Pragmatic Reasons & & & & $\begin{array}{l}\text { Factor } \\
\text { Loadings }\end{array}$ \\
\hline $\begin{array}{l}\text { Would you agree to movies without subtitles, if } \\
\text { abandoning the subtitling would make the } \\
\text { tickets cheaper by } 25 \text { kroons? }\end{array}$ & & & & 0.70 \\
\hline $\begin{array}{l}\text { Would you buy a mobile phone with an English } \\
\text { menu if it would cost } 5 \% \text { less than the same } \\
\text { phone with an Estonian menu? }\end{array}$ & & & & 0.67 \\
\hline $\begin{array}{l}\text { Do you read Estonian subtitles when you are } \\
\text { watching movies in English? }\end{array}$ & & & & $(-0.61)$ \\
\hline definitely yes & rather yes & & rather not & definitely not \\
\hline $27 \%$ & $27 \%$ & & $31 \%$ & $14 \%$ \\
\hline
\end{tabular}


Estonian staff who communicated daily with

influential foreign customers, would you set

English as the internal working language for your company?

If you knew that the foreign owner of the

company you are working for was to call you

shortly, would you answer the phone in

English for his sake?

If your superiors required reports written in

English, would you require the same from your subordinates?

$\begin{array}{cccc}\text { definitely yes } & \text { rather yes } & \text { rather not } & \text { definitely not } \\ 8 \% & 24 \% & 46 \% & 21 \%\end{array}$

Factor

F7: The Prestige of Education in English

Loadings

Would you enrol your child in an English school

if it had the same high teaching standard and

was as close to home as an Estonian school?

Would you put your child into an

English-language day care centre?

Should your child acquire his/her higher

education abroad?

If you could acquire a university degree in your

favourite speciality either in Estonian or in

English, would you prefer English?

$$
\begin{gathered}
\text { definitely yes } \\
12 \%
\end{gathered}
$$

rather yes

$32 \%$
rather not
$41 \%$

definitely not $15 \%$

Factor

F11: Usage of Estonian in a Mixed Family

Loadings

If your future spouse were not Estonian, would

she or he have to learn to speak Estonian?

If your future spouse were not Estonian, would it

be important for you to teach your child

Estonian?

If your future spouse were not Estonian, would

the common language in your family have to

be Estonian?

$$
\begin{gathered}
\text { definitely yes } \\
44 \%
\end{gathered}
$$

rather yes
$42 \%$

rather not

definitely not

$11 \%$

$3 \%$

aThe factor loadings can be interpreted as the relation between the initial variable (single question) and the factor (the new variable based on a set of related variables) whereby the closer the absolute value is to 1 , the bigger the influence of a particular question in that factor. The factor loadings of excluded variables are in parentheses. ${ }^{b}$ Movies in Estonian cinemas have the original soundtrack, but they are all subtitled. Twenty-five kroons would be around $25 \%$ of the average ticket price. 
APPENDIX B

Average Values of Factors by Demographic Variables Where the Subgroups Have Statistically Significant Differences $(p<.05)^{\mathrm{a}}$

\begin{tabular}{|c|c|c|c|c|c|}
\hline Social Variables & $F 1$ & $F 2$ & F4 & $F 7$ & F11 \\
\hline \multicolumn{6}{|l|}{ Age } \\
\hline 15 & & & .05 & & \\
\hline 16 & & & $.12_{(4,5)}$ & & \\
\hline 17 & & & $.09_{(4)}$ & & \\
\hline 18 & & & $-.15_{(2,3)}$ & & \\
\hline 19 & & & $-.20_{(2)}$ & & \\
\hline \multicolumn{6}{|l|}{ Gender } \\
\hline Male & & $.12_{(2)}$ & & & \\
\hline Female & & $-.09_{(1)}$ & & & \\
\hline \multicolumn{6}{|l|}{ School } \\
\hline Ordinary & $-.07_{(2)}$ & $-.08_{(2)}$ & & .01 & \\
\hline English tuition extended & $.61_{(1,3)}$ & $.46_{(1,3)}$ & & $.19_{(3)}$ & \\
\hline Other subjects extended & $-.04_{(2)}$ & $-.02_{(2)}$ & & $-.06_{(2)}$ & \\
\hline \multicolumn{6}{|l|}{ Settlement } \\
\hline City & $.11_{(3)}$ & $.21_{(2,3)}$ & $-.12(3)$ & & $.09_{(3)}$ \\
\hline Town & .00 & $-.03_{(1,3)}$ & .00 & & $.11_{(3)}$ \\
\hline Rural & $-.09_{(1)}$ & $-.16_{(1,2)}$ & $.10_{(1)}$ & & $-.19_{(1,2)}$ \\
\hline \multicolumn{6}{|l|}{ Parents' income } \\
\hline Above average & $.14_{(2,3)}$ & & & $.15_{(2)}$ & \\
\hline Average & $-.02_{(1)}$ & & & $-.04_{(1)}$ & \\
\hline Below average & $-.10_{(1)}$ & & & -.03 & \\
\hline \multicolumn{6}{|l|}{ Parents' education } \\
\hline Both higher & $.19_{(2,3,4)}$ & $.23_{(2,3,4)}$ & & & \\
\hline One higher & $-.03_{(1)}$ & $.04_{(1,4)}$ & & & \\
\hline Both secondary & $.04_{(1)}$ & $-.08_{(1)}$ & & & \\
\hline Other & $-.16_{(1)}$ & $-.27_{(1,2)}$ & & & \\
\hline
\end{tabular}

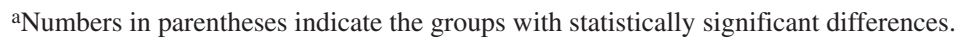

